\title{
Performance Analysis of T20-World Cup Cricket 2012
}

\author{
Ananda B. W. Manage*, Stephen M. Scariano and Cecil R. Hallum
}

Sam Houston State University

Huntsville, Texas, USA 77341

Corresponding Author (Email: wxb001@shsu.edu)

Received: 13 February 2013 / Revised: 15 May 2013

\begin{abstract}
Performance analysis of cricket players is always an intricate task due to the correlated nature of the variables used to quantify contributions to the team. Lack of transparency of current methods, probably due to commercial confidentiality, creates a necessity for new and lucent evaluative methods. Here, we present a simple, yet straightforward, method for analyzing the performance of T20-World Cup Cricket 2012 players that can be easily adapted to other team sports.
\end{abstract}

Keywords: Cricket, Principal Component Analysis, Ranking Methods.

\section{Introduction}

Quantifying individual player contributions to a team is an important yet difficult task in all team sports. Usually, there are several indicators available to measure player performances, which are based on different aspects of their contributions to the team. Unfortunately these indicators are mostly related to each other in a manner that oftentimes causes difficulty in constructing an overall performance measure. Our idea is to use a tool acquired from multivariate statistical analysis and apply it directly to T20-World Cup Cricket 2012 data. In this method, the first principal component is used to rank batsmen and bowlers. The technique is simple and can be directly applied to the type of correlated data routinely found in team sports such as cricket. Cricket administrators and sports analysts can use this amenable method to quantify players' contribution, which could lead to a ranking structure based on their performances.

There has been a fair amount of research done on performance analysis of cricket players in the literature. The International Cricket Council (ICC) maintains a dynamic ranking system separately for bowlers, batsmen and all-rounders for each format of cricket. Bennet (1998, pp. 93-95) has an excellent discussion on this topic. Borooah and Mangan (2010) address some key issues related to evaluating batsmen for test matches, while van Staden (2008) discusses a graphical method for comparing bowlers, batsmen and all-rounders.. Lakkaraju and Sethi (2012) present an application of Sabermetrics-style principals to the game of cricket. 
The general scarcity of the details regarding currently used ranking methods, probably due to commercial confidentiality, creates a need for new and readily available ranking methods. In contrast, the simplicity and the openness of the proposed method would make it an attractive alternative for the cricket playing community. We will compare and contrast our proposed method with the T20World Cup 2012 analysis published at ESPN at http://www.espncricinfo.com/iccworld-twenty20-2012/content/story/586148.html by Madhusudhan Ramakrishnan, who is a sub-editor (stats) at ESPNcricinfo. To make the reference more compact, this ranking method is abbreviated as the "MR-ranking".

\section{Ranking using the First Principal Component}

Readers can find excellent introductions to Principal Component Analysis (PCA) in the works of Johnson and Wichern (2007), Dawkins (1989), and Watnik and Levine (2001). Nalik \& Khattree (1999) provide an example in which principal component analysis is used with sports data. PCA is a wide area in statistical science, and there are many other excellent reference sources as well.

Briefly, if $\boldsymbol{X}^{\prime}=\left[X_{1}, X_{2}, \ldots, X_{k}\right]$ is a k-vector of random variables with variancecovariance matrix $\Sigma$ and corresponding eigenvalue-eigenvector pairs $\left(\delta_{1}, \boldsymbol{e}_{1}\right),\left(\delta_{2}, \boldsymbol{e}_{2}\right), \ldots,\left(\delta_{k}, \boldsymbol{e}_{\boldsymbol{k}}\right)$, where $\delta_{1} \geq \delta_{2} \geq \cdots \geq \delta_{k}$, then the principal components $P_{1}, P_{2}, \ldots, P_{k}$ are defined by

$P_{i}=\boldsymbol{e}_{\boldsymbol{i}}^{\prime} \boldsymbol{X}, \quad i=1,2, \ldots, k$

Furthermore, it can be shown that

$$
\begin{aligned}
& \operatorname{Var}\left(P_{i}\right)=\boldsymbol{e}_{\boldsymbol{i}}^{\prime} \sum \boldsymbol{e}_{\boldsymbol{i}}=\delta_{i}, \quad i=1,2, \ldots, k \\
& \operatorname{Cov}\left(P_{i}, P_{j}\right)=0, \quad i \neq j \\
& \sum_{i=1}^{k} \operatorname{Var}\left(X_{i}\right)=\operatorname{trace}\left(\sum\right)=\sum_{i=1}^{k} \operatorname{Var}\left(P_{i}\right)=\delta_{1}+\delta_{2}+\cdots+\delta_{k}
\end{aligned}
$$

Consequently, the proportion of total variability due to the $i^{\text {th }}$ principal component is given by

$$
T_{i}=\frac{\delta_{i}}{\delta_{1}+\delta_{2}+\cdots+\delta_{k}}
$$

If the first principle component captures a substantial percentage of the total variation in the observations, it can possibly be used to discriminate between the $\mathrm{k}$ vectors. Indeed, if $T_{1}$ accounts for most of the variation seen in the data, then there is good reason to believe that it can successfully be used for ranking purposes. For this reason, we call this technique the First Principal Component (FPC) ranking method. In practice, it is customary to use the correlation matrix instead of the variance-covariance matrix when the measurement units for the components of the 
$\boldsymbol{X}$ data vector are largely dissimilar. For this reason, the correlation matrix is used in this analysis.

\section{Ranking Batsmen}

The MR-ranking method uses a point system to quantify the contributions of cricket players. Unfortunately, the calculative method of assignment of points to a player is not explicitly disclosed. Table 1 shows the MR-ranking for the top ten batsmen who scored a minimum of one hundred runs in the T20-World Cup 2012. The key variables seen are Innings, Runs, Average, Strike Rate and Points (assigned by the MR-ranking). For this method, Marlon Samuels is the top batsman followed by Chris Gayle.

Table 1: MR-ranking of Top Ten Batsmen in T20-World Cup 2012 (min 100 runs)

\begin{tabular}{|l|c|c|c|c|c|}
\hline & Innings & Runs & Average & $\begin{array}{c}\text { Strike } \\
\text { Rate }\end{array}$ & $\begin{array}{c}\text { MR } \\
\text { Points }\end{array}$ \\
\hline Marlon Samuels & 6 & 230 & 38.3 & 132.94 & 26.16 \\
\hline Chris Gayle & 6 & 222 & 44.4 & 150.00 & 24.32 \\
\hline Shane Watson & 6 & 249 & 49.8 & 150.00 & 23.24 \\
\hline Brendon McCullum & 5 & 212 & 42.4 & 159.39 & 22.97 \\
\hline Virat Kohli & 5 & 185 & 46.3 & 122.51 & 20.49 \\
\hline Luke Wright & 5 & 193 & 48.3 & 169.29 & 20.36 \\
\hline Mahela Jayawardene & 7 & 243 & 40.5 & 116.26 & 17.91 \\
\hline Ross Taylor & 5 & 147 & 49.0 & 145.54 & 16.98 \\
\hline Suresh Raina & 4 & 110 & 36.7 & 126.43 & 15.90 \\
\hline Michael Hussey & 5 & 155 & 77.5 & 123.01 & 15.81 \\
\hline
\end{tabular}

Although the variables shown in Table 1 are undoubtedly important ones, there are several other variables that carry information about the contributions to a team by a batsman, and some of the variables may, indeed, be correlated. Here, we use the correlation matrix to accommodate discrepancies in the magnitudes of the measurement units of the variables. Below is a brief description of our selection for the critical variables used to quantify the quality of batsmen.

Runs: Total number of runs scored in the T20-World Cup 2012.

Batting Average (Ave): Total number of runs a batsman has scored divided by the total number of innings in the T20-World Cup 2012 (It is only the number of innings where the batsman was called out). Note that this number overrates the performance of a batsman with several "not out" cases, which is a weakness in this measure. 
Batting Strike Rate (SR): The number of runs scored per 100 balls faced in the T20-World Cup 2012. Higher values of SR indicate stronger performance, as an aggressive batting style is always advantageous in shorter versions of limited-overs cricket matches like T20.

Fours: Total number of boundaries (fours) made in the T20-World Cup 2012. Hitting boundaries is also auspicious for winning in limited-overs cricket.

Sixes: Total number of sixes made in the T20 World Cup 2012. An adroit batsman continually strives to hit sixes, which is a desirable characteristic of a quality batsman, especially in a shorter format of limited-overs cricket matches like T20.

HF: Denotes the calculation (2x Number of Centuries + Number of Fifties). It is always good to build partnerships and play longer innings in any format of cricket. In this tournament, there was only one century by New Zealand batsman Brendon McCullum who scores 123 runs against Bangladesh. Since there was only one century (100 or more runs), we created the variable "HF" to include the combined information carried by the total number of centuries and half-centuries (50 or more runs but less than 100 runs in an innings).

All batsmen who played at least three innings in the T20-World Cup 2012 were included in this analysis, so that fifty-seven total batsmen comprise this list. For each batsman we collected ( $6 \times 1)$ column vectors of the form $\boldsymbol{X}=$ (Runs, Ave, SR, Fours, Sixes, HF)', and using them computed the sample correlation matrix with $\mathrm{SAS}^{\circledR}$ 9.2. Next, we obtained all eigenvalues and associated eigenvectors for the correlation matrix and identified the largest eigenvalue, $\delta_{1}=4.0167$, as well as its corresponding eigenvector $\boldsymbol{e}_{\mathbf{1}}=[0.471,0.380,0.299,0.402,0.432]$ '. The latent value $\delta_{1}$ was the only eigenvalue exceeding 1.0 and $\mathrm{SAS}^{\circledR} 9.2$ reports that the first principal component $P_{1}=\boldsymbol{e}_{\mathbf{1}}^{\prime} \boldsymbol{X}$ accounts for $66.9 \%$ of the total variability identified in equation (1). So, it is plausible to concentrate on just the First Principal Component (FPC), as it accounts for a substantial portion of the total variability. Accordingly, we choose to rank the T20-World Cup 2012 batsmen based on their individual scores produces by the first principal component computation. Table 2 extracts from Table 3, which provides the FPC-rankings for all 57 batsmen who played at least three innings, the top ten batsmen who scored at least one hundred total runs along with their FPC-rankings.

A glance at Table 1 and Table 2 reveals that eight out of ten players appear in both, although the rank orderings of the batsmen is slightly different. Unlike the MRrankings, the FPC-rankings capture essential statistical information about the batsmen in a straightforward manner that can be easily checked. Here are some key differences in the techniques that demonstrate the superiority of the FPC method: 
Table 2: FPC-ranking of Top Ten Batsmen in T20-World Cup 2012 (min 100 runs)

\begin{tabular}{|c|c|c|c|c|c|c|c|c|c|}
\hline Batsman (MR Ranking) & Innings & $\begin{array}{l}\text { Not } \\
\text { Out }\end{array}$ & Runs & Ave & $\begin{array}{c}\text { Strike } \\
\text { Rate }\end{array}$ & Fours & Sixes & $\mathbf{H F}$ & FPC Rank \\
\hline Shane Watson (3) & 6 & 1 & 249 & 49.8 & 150.0 & 19 & 15 & 3 & 5.32 \\
\hline Chris Gayle (2) & 6 & 1 & 222 & 44.4 & 150.0 & 19 & 16 & 3 & 5.09 \\
\hline Marlon Samuels (1) & 6 & 0 & 230 & 38.3 & 132.9 & 14 & 15 & 3 & 4.32 \\
\hline Luke Wright (6) & 5 & 1 & 193 & 48.3 & 169.3 & 14 & 13 & 2 & 4.08 \\
\hline Brendon McCullum (4) & 5 & 0 & 212 & 42.4 & 159.4 & 20 & 10 & 2 & 3.97 \\
\hline Mahela Jayawardene (7) & 7 & 1 & 243 & 40.5 & 116.3 & 29 & 5 & 1 & 3.02 \\
\hline Virat Kohli (5) & 5 & 1 & 185 & 46.3 & 122.5 & 20 & 4 & 2 & 2.66 \\
\hline Michael Hussey (10) & 5 & 3 & 155 & 77.5 & 123.0 & 12 & 4 & 1 & 2.22 \\
\hline Imran Nazir (not in top 10) & 6 & 0 & 153 & 25.5 & 150.0 & 24 & 3 & 1 & 1.91 \\
\hline Nasir Jamshed (not in top 10) & 6 & 1 & 148 & 29.6 & 134.5 & 8 & 8 & 2 & 1.82 \\
\hline
\end{tabular}


Marlon Samuels \& Shane Watson: Marlon Samuels and Shane Watson have MRrankings 1 and 3, respectively, yet their FPC-rankings are just the opposite, 3 and 1, respectively. Watson scored 249 total runs with an average of 49.8 runs, and a strike rate of 150 . He hit three half-centuries, 19 boundaries and 15 sixes. Marlon Samuels scored a total of 230 runs with an average 38.3 runs, and a strike rate of 132.9. He hit three half-centuries, 14 boundaries and 15 sixes. Clearly, Watson has higher total runs, higher strike rate and more sixes, while Samuels is not superior in terms of any variables that we considered in the analysis. Therefore, Watson should be ranked higher than Samuels.

Suresh Raina \& Nasir Jamshed: Suresh Raina is ranked ninth of the top ten batsmen by MR-method. However, he does not appear in the top ten list of batsmen using the FPC-rankings. Raina scored 110 total runs with an average 36.7 runs, and a strike rate of 126.4. He hit no half-centuries or centuries nor did he score any boundaries or sixes. Now, compare Raina's performance to that of Nasir Jamshed, whose rank is tenth in Table 2 when using the FPC method. Jamshed scored 148 total runs with an average 29.6 runs, and a strike rate of 134.5. He hit two halfcenturies, scored 8 boundaries as well as 8 sixes. So, Jamshed has a better strike rate, two half-centuries, 8 sixes and 8 boundaries when compared to Raina who scored no half-centuries or centuries and no sixes or boundaries. Therefore, Jamshed should be ranked higher than Raina. Accordingly, Riana does not appear in the top ten list of batsmen when using FPC-ranking.

Virat Kohli \& Luke Wright: Virat Kohli is ranked above Luke Wright in the MRrankings, but the order is reversed for the FPC-rankings. Kohli scored 185 total runs with an average 46.3 runs, and a strike rate of 122.5. He hit 2 half-centuries, and scored 20 boundaries and 4 sixes. On the other hand, Wright scored 193 total runs with an average 48.3 runs, and a strike rate of 169.3. He hit 2 half-centuries, and scored 14 boundaries and 13 sixes. In fact, Wright has a better average, strike rate and also more sixes than Kohli. The strike rate and number of sixes are extremely important factors in the shorter formats of cricket like Twenty20. Therefore, Wright should be ranked higher than Kohli, which we see in the FPC-rankings of these two batsmen.

Ross Taylor: Ross Taylor is ranked eighth in the MR-rankings, but he does not appear in the top ten list of FCP-rankings because he ranks eleventh. The FPCranking method selects Nasir Jamshed, who is the tenth, above Taylor since he scored two half-centuries to just one half-century by Taylor.

\section{Ranking Bowlers}

Comparisons of MR-rankings and FPC rankings are now considered for T20-World Cup 2012 bowlers. Table 4 shows the top ten list for the MR point system when quantifying contributions of bowlers who bowled at least 15 overs in the T20 World Cup 2012. Here, Ajantha Mendis, who is also the highest wicket-taker, is ranked first. 
Table 3: FPC-ranking of T20-World Cup 2012 Batsmen who played at least innings

\begin{tabular}{|c|c|c|c|c|c|c|c|}
\hline Player & Runs & Ave & SR & Fours & Sixes & $\mathbf{H F}$ & $\begin{array}{l}\text { FPC } \\
\text { Rank }\end{array}$ \\
\hline SR Watson (Aus) & 249 & 49.8 & 150.0 & 19 & 15 & 3 & 5.32 \\
\hline CH Gayle (WI) & 222 & 44.4 & 150.0 & 19 & 16 & 3 & 5.09 \\
\hline MN Samuels (WI) & 230 & 38.3 & 132.9 & 14 & 15 & 3 & 4.32 \\
\hline LJ Wright (Eng) & 193 & 48.3 & 169.3 & 14 & 13 & 2 & 4.08 \\
\hline BB McCullum (NZ) & 212 & 42.4 & 159.4 & 20 & 10 & 2 & 3.97 \\
\hline DPMD Jayawardene (SL) & 243 & 40.5 & 116.3 & 29 & 5 & 1 & 3.02 \\
\hline V Kohli (India) & 185 & 46.3 & 122.5 & 20 & 4 & 2 & 2.66 \\
\hline MEK Hussey (Aus) & 155 & 77.5 & 123.0 & 12 & 4 & 1 & 2.22 \\
\hline Imran Nazir (Pak) & 153 & 25.5 & 150.0 & 24 & 3 & 1 & 1.91 \\
\hline Nasir Jamshed (Pak) & 148 & 29.6 & 134.5 & 8 & 8 & 2 & 1.82 \\
\hline LRPL Taylor (NZ) & 147 & 49.0 & 145.5 & 12 & 4 & 1 & 1.76 \\
\hline TM Dilshan (SL) & 179 & 25.6 & 120.9 & 17 & 4 & 1 & 1.35 \\
\hline GJ Bailey (Aus) & 84 & 42.0 & 171.4 & 8 & 5 & 1 & 1.34 \\
\hline DA Warner (Aus) & 131 & 26.2 & 127.2 & 15 & 5 & 1 & 1.09 \\
\hline EJG Morgan (Eng) & 140 & 35.0 & 126.1 & 7 & 7 & 1 & 1.08 \\
\hline Umar Akmal (Pak) & 125 & 62.5 & 120.2 & 11 & 3 & 0 & 0.87 \\
\hline J Charles (WI) & 130 & 21.7 & 112.1 & 18 & 4 & 1 & 0.82 \\
\hline KC Sangakkara (SL) & 170 & 28.3 & 126.9 & 18 & 1 & 0 & 0.64 \\
\hline JEC Franklin (NZ) & 120 & 30.0 & 127.7 & 9 & 4 & 1 & 0.62 \\
\hline AD Hales (Eng) & 124 & 24.8 & 124.0 & 13 & 2 & 1 & 0.49 \\
\hline DJ Bravo (WI) & 134 & 33.5 & 118.6 & 8 & 7 & 0 & 0.43 \\
\hline Mohammad Hafeez (Pak) & 164 & 27.3 & 98.2 & 15 & 4 & 0 & 0.31 \\
\hline RJ Nicol (NZ) & 105 & 26.3 & 119.3 & 7 & 5 & 1 & 0.27 \\
\hline RG Sharma (India) & 82 & 41.0 & 130.2 & 7 & 1 & 1 & 0.19 \\
\hline SK Raina (India) & 110 & 36.7 & 126.4 & 15 & 0 & 0 & 0.1 \\
\hline JP Duminy (SA) & 106 & 35.3 & 116.5 & 7 & 3 & 0 & -0.27 \\
\hline RJ Peterson (SA) & 45 & 45.0 & 136.4 & 7 & 0 & 0 & -0.53 \\
\hline BMAJ Mendis (SL) & 94 & 23.5 & 120.5 & 9 & 2 & 0 & -0.59 \\
\hline MS Dhoni (India) & 65 & 32.5 & 127.5 & 8 & 1 & 0 & -0.65 \\
\hline AB de Villiers (SA) & 89 & 22.3 & 130.9 & 5 & 3 & 0 & -0.66 \\
\hline KA Pollard (WI) & 80 & 13.3 & 133.3 & 8 & 3 & 0 & -0.73 \\
\hline CL White (Aus) & 60 & 30.0 & 122.4 & 6 & 2 & 0 & -0.84 \\
\hline Umar Gul (Pak) & 46 & 23.0 & 139.4 & 3 & 4 & 0 & -0.85 \\
\hline RE Levi (SA) & 62 & 20.7 & 103.3 & 7 & 0 & 1 & -0.98 \\
\hline NLTC Perera (SL) & 52 & 17.3 & 144.4 & 3 & 3 & 0 & -0.99 \\
\hline DJG Sammy (WI) & 54 & 18.0 & 142.1 & 5 & 1 & 0 & -1.09 \\
\hline G Gambhir (India) & 80 & 16.0 & 111.1 & 10 & 0 & 0 & -1.19 \\
\hline Yuvraj Singh (India) & 66 & 22.0 & 108.2 & 4 & 3 & 0 & -1.22 \\
\hline AD Mathews (SL) & 51 & 25.5 & 124.4 & 4 & 1 & 0 & -1.24 \\
\hline HM Amla (SA) & 71 & 17.8 & 109.2 & 8 & 1 & 0 & -1.25 \\
\hline F Behardien (SA) & 62 & 31.0 & 103.3 & 5 & 1 & 0 & -1.25 \\
\hline MJ Guptill (NZ) & 75 & 18.8 & 97.4 & 9 & 1 & 0 & -1.31 \\
\hline JA Morkel (SA) & 19 & 19.0 & 158.3 & 1 & 1 & 0 & -1.34 \\
\hline AD Russell (WI) & 35 & 17.5 & 134.6 & 2 & 2 & 0 & -1.43 \\
\hline V Sehwag (India) & 54 & 18.0 & 112.5 & 6 & 1 & 0 & -1.45 \\
\hline Kamran Akmal (Pak) & 64 & 12.8 & 110.3 & 5 & 1 & 0 & -1.61 \\
\hline Shahid Afridi (Pak) & 30 & 6.0 & 136.4 & 5 & 0 & 0 & -1.77 \\
\hline Shoaib Malik (Pak) & 59 & 19.7 & 90.8 & 5 & 0 & 0 & -1.86 \\
\hline JC Buttler (Eng) & 40 & 13.3 & 114.3 & 4 & 0 & 0 & -1.89 \\
\hline HDRL Thirimanne (SL) & 27 & 9.0 & 128.6 & 2 & 1 & 0 & -1.9 \\
\hline NL McCullum (NZ) & 29 & 9.7 & 116.0 & 1 & 2 & 0 & -2.01 \\
\hline C Kieswetter (Eng) & 39 & 9.8 & 83.0 & 4 & 2 & 0 & -2.22 \\
\hline JM Bairstow (Eng) & 38 & 9.5 & 82.6 & 4 & 1 & 0 & -2.35 \\
\hline JDP Oram (NZ) & 23 & 7.7 & 104.5 & 3 & 0 & 0 & -2.37 \\
\hline KS Williamson (NZ) & 36 & 12.0 & 90.0 & 3 & 0 & 0 & -2.37 \\
\hline JH Kallis (SA) & 24 & 8.0 & 72.7 & 2 & 1 & 0 & -2.76 \\
\hline D Ramdin (WI) & 8 & 4.0 & 100.0 & 0 & 0 & 0 & -2.83 \\
\hline
\end{tabular}


Paralleling the scrutiny given batsmen, there are several, potentially correlated, variables that carry the information about team contributions by bowlers. Again, we use the correlation matrix to accommodate for discrepancies in the magnitudes of the measurement units of the variables. Here is a brief description of the critical variables used to quantify the quality of the bowlers.

Wickets: The number of wickets taken. A bowler's goal is to obtain as many as wickets as possible.

Bowling Average (Ave): The average number of runs conceded per wicket. Better bowlers have lower averages.

Strike Rate (SR): The average number of balls bowled per wicket taken. Better bowlers have lower strike rates.

Economy Rate (Econ): The average number of runs conceded per over. Better bowlers have lower economy rate.

Table 4: MR-ranking of Top Ten Bowlers in T20-World Cup 2012 (min 15 overs)

\begin{tabular}{|l|c|c|c|c|c|}
\hline \multicolumn{1}{|c|}{ Bowler } & Matches & Wickets & Average & $\begin{array}{c}\text { Economy } \\
\text { Rate }\end{array}$ & MR Points \\
\hline Ajantha Mendis & 6 & 15 & 9.80 & 6.12 & 35.65 \\
\hline Sunil Narine & 7 & 9 & 15.44 & 5.63 & 27.90 \\
\hline Samuel Badree & 4 & 4 & 22.25 & 5.56 & 27.53 \\
\hline Steve Finn & 5 & 8 & 15.37 & 6.15 & 27.22 \\
\hline Shane Watson & 6 & 11 & 16.00 & 7.33 & 25.94 \\
\hline Raza Hasan & 4 & 3 & 24.66 & 4.93 & 25.83 \\
\hline Graeme Swann & 5 & 7 & 16.71 & 6.15 & 25.27 \\
\hline Mitchell Starc & 6 & 10 & 16.40 & 6.83 & 24.64 \\
\hline Saeed Ajmal & 6 & 9 & 18.11 & 6.79 & 23.42 \\
\hline Dale Steyn & 5 & 6 & 13.66 & 4.82 & 23.07 \\
\hline
\end{tabular}

All bowlers who bowled at least ten overs in the T20-World Cup 2012 were included in this analysis, so that forty-one total bowlers comprise this list. For each bowler, we collected ( $4 \times 1$ ) column vectors of the form $\boldsymbol{X}=$ (Wickets, Ave, SR, Econ)', and using them computed the sample correlation matrix with $\operatorname{SAS}^{\circledR}$ 9.2. Next, we obtained all eigenvalues and associated eigenvectors for the correlation matrix and identified the largest eigenvalue, $\delta_{1}=2.5898$, as well as its corresponding eigenvector $\boldsymbol{e}_{\mathbf{1}}=[-0.508,0.601,0.205,0.582]^{\prime}$. Eigenvalue $\delta_{1}$ was the only one exceeding 1.0, and SAS ${ }^{\circledR} 9.2$ reports that the first principal component $P_{1}=\boldsymbol{e}_{\mathbf{1}}^{\prime} \boldsymbol{X}$ accounts $64.7 \%$ of the total variability identified in equation (1). So, it is reasonable to focus on just the First Principal Component (FPC) since it accounts for a pertinent amount of the total variability. Accordingly, we choose to rank the T20-World Cup 2012 bowlers based on their individual first principal component scores. Table 6 gives the FPC-rankings for all 41 bowlers who bowled at least ten 
overs, but for purposes of direct comparison with the MR-rankings in Table 4, Table 5 extracts from Table 6 the top ten bowlers who bowled at least fifteen overs along with their FPC-rankings. Sri Lankan spinner Ajantha Mendis is seen to be the top bowler for both ranking methods. Additionally, eight of ten bowlers match in Table 4 and Table 5, although the rank orderings are different. Just as with the batsmen, the FPC-rankings capture essential statistical information about the bowlers in a genuine way that can be confirmed easily.

Table 5: FPC-ranking of Top Ten Bowlers in T20 World Cup 2012 (min 15 overs)

\begin{tabular}{|l|c|c|c|c|c|c|}
\hline $\begin{array}{c}\text { Bowler (MR } \\
\text { Ranking) }\end{array}$ & Overs & Wickets & Average & $\begin{array}{c}\text { Economy } \\
\text { Rate }\end{array}$ & $\begin{array}{c}\text { Strike } \\
\text { Rate }\end{array}$ & $\begin{array}{c}\text { FPC } \\
\text { Rank }\end{array}$ \\
\hline Ajantha Mendis (1) & 24.0 & 15 & 9.8 & 6.12 & 9.6 & -2.98 \\
\hline Shane Watson (5) & 24.0 & 11 & 16.0 & 7.33 & 13.0 & -1.70 \\
\hline Mitchell Starc (8) & 24.0 & 10 & 16.4 & 6.83 & 14.4 & -1.52 \\
\hline Sunil Narine (2) & 24.4 & 9 & 15.4 & 5.63 & 16.4 & -1.49 \\
\hline Steve Finn (4) & 20.0 & 8 & 15.4 & 6.15 & 15.0 & -1.28 \\
\hline Saeed Ajmal (9) & 24.0 & 9 & 18.1 & 6.79 & 16.0 & -1.22 \\
\hline Dale Steyn (10) & 17.0 & 6 & 13.7 & 4.82 & 17.0 & -1.11 \\
\hline Graeme Swann (7) & 19.0 & 7 & 16.7 & 6.15 & 16.2 & -1.00 \\
\hline $\begin{array}{l}\text { Timothy Southee } \\
\text { (not in top 10) }\end{array}$ & 18.0 & 8 & 18.0 & 8.00 & 13.5 & -0.95 \\
\hline $\begin{array}{l}\text { Ravi Rampaul (not } \\
\text { in top 10) }\end{array}$ & 23.5 & 9 & 21.0 & 7.93 & 15.8 & -0.94 \\
\hline
\end{tabular}

As with the batsmen, here are some key differences in the techniques that demonstrate the superiority of the FPC method:

Samuel Badree \& Ravi Rampaul: Samuel Badree is ranked number three in the MR-rankings but does not appear in the list of top ten bowlers when using the FPC method. Badree bowled 16.0 overs and took 4 wickets with an average of 22.3. His economy rate is 5.56, and his strike rate is 24.0. On the other hand, Rampaul, who ranks tenth in the FPC-ranking method bowled 23.5 overs and took 9 wickets with an average of 22.0. His economy rate is 7.93, and his strike rate is 15.8. So, Badree is better than Rampaul only with respect to the economy rate variable, which is the number of runs per over. It is true that a low economy rate is a desirable attribute. However, Rampaul has a lower average, which is better since it represents the number of runs conceded per wicket. Moreover, Rampaul has the lower strike rate, which is the average number of balls per wicket. In addition, Rampaul has taken 9 wickets for 23.5 overs, while Badree has taken just 4 wickets for 16.0 overs. This justifies that Rampaul should be ranked higher than Badree.

Mitchell Starc: Michell Starc is ranked seventh in the MR-rankings yet ranked third in the FPC-rankings. Starc has taken 10 wickets, which is the third highest 
number in all the tournament. His average is 16.4, economy rate is 6.83 and strike rate is 14.4 , which are smaller values when compared to the top ten bowlers.

Table 6: FPC-ranking of T20 World Cup 2012 Bowlers (min 10 overs)

\begin{tabular}{|c|c|c|c|c|c|c|}
\hline Bowler & Overs & Wickets & Average & $\begin{array}{l}\text { Economy } \\
\text { Rate }\end{array}$ & $\begin{array}{l}\text { Strike } \\
\text { Rate }\end{array}$ & $\begin{array}{l}\text { FPC } \\
\text { Rank } \\
\end{array}$ \\
\hline BAW Mendis (SL) & 24.0 & 15 & 9.8 & 6.12 & 9.6 & -2.98 \\
\hline L Balaji (India) & 12.0 & 9 & 9.8 & 7.33 & 8.0 & -1.76 \\
\hline Yuvraj Singh (India) & 13.4 & 8 & 10.1 & 5.92 & 10.2 & -1.71 \\
\hline SR Watson (Aus) & 24.0 & 11 & 16.0 & 7.33 & 13.0 & -1.70 \\
\hline MA Starc (Aus) & 24.0 & 10 & 16.4 & 6.83 & 14.4 & -1.52 \\
\hline SP Narine (WI) & 24.4 & 9 & 15.4 & 5.63 & 16.4 & -1.49 \\
\hline JH Kallis (SA) & 11.0 & 7 & 10.4 & 6.63 & 9.4 & -1.43 \\
\hline ST Finn (Eng) & 20.0 & 8 & 15.4 & 6.15 & 15.0 & -1.28 \\
\hline Saeed Ajmal (Pak) & 24.0 & 9 & 18.1 & 6.79 & 16.0 & -1.22 \\
\hline DW Steyn (SA) & 17.0 & 6 & 13.7 & 4.82 & 17.0 & -1.11 \\
\hline GP Swann (Eng) & 19.0 & 7 & 16.7 & 6.15 & 16.2 & -1.00 \\
\hline TG Southee (NZ) & 18.0 & 8 & 18.0 & 8.00 & 13.5 & -0.95 \\
\hline R Rampaul (WI) & 23.5 & 9 & 21.0 & 7.93 & 15.8 & -0.94 \\
\hline A Dananjaya (SL) & 11.0 & 5 & 14.8 & 6.72 & 13.2 & -0.74 \\
\hline BMAJ Mendis (SL) & 11.0 & 5 & 14.8 & 6.72 & 13.2 & -0.74 \\
\hline SCJ Broad (Eng) & 19.0 & 7 & 20.1 & 7.42 & 16.2 & -0.68 \\
\hline RJ Peterson (SA) & 13.0 & 5 & 17.8 & 6.84 & 15.6 & -0.51 \\
\hline R Ashwin (India) & 15.5 & 5 & 19.0 & 6.00 & 19.0 & -0.46 \\
\hline SL Malinga (SL) & 24.3 & 8 & 25.9 & 8.44 & 18.3 & -0.40 \\
\hline XJ Doherty (Aus) & 11.0 & 5 & 19.0 & 8.63 & 13.2 & -0.28 \\
\hline Mohammad Hafeez (Pak) & 18.0 & 5 & 21.4 & 5.94 & 21.6 & -0.28 \\
\hline M Morkel (SA) & 16.4 & 5 & 21.8 & 6.54 & 20.0 & -0.24 \\
\hline S Badree (WI) & 16.0 & 4 & 22.3 & 5.56 & 24.0 & -0.03 \\
\hline IK Pathan (India) & 14.0 & 5 & 24.2 & 8.64 & 16.8 & 0.05 \\
\hline JDP Oram (NZ) & 12.3 & 5 & 24.2 & 9.68 & 15.0 & 0.15 \\
\hline NL McCullum (NZ) & 17.0 & 4 & 26.0 & 6.11 & 25.5 & 0.26 \\
\hline KMDN Kulasekara (SL) & 22.0 & 5 & 29.0 & 6.59 & 26.4 & 0.30 \\
\hline Raza Hasan (Pak) & 15.0 & 3 & 24.7 & 4.93 & 30.0 & 0.39 \\
\hline PJ Cummins (Aus) & 24.0 & 6 & 32.8 & 8.20 & 24.0 & 0.41 \\
\hline CH Gayle (WI) & 10.2 & 3 & 26.3 & 7.64 & 20.6 & 0.49 \\
\hline AD Mathews (SL) & 20.0 & 4 & 29.8 & 5.95 & 30.0 & 0.55 \\
\hline DJG Sammy (WI) & 17.0 & 4 & 32.8 & 7.70 & 25.5 & 0.75 \\
\hline KD Mills (NZ) & 16.0 & 4 & 32.8 & 8.18 & 24.0 & 0.76 \\
\hline Z Khan (India) & 13.0 & 3 & 31.3 & 7.23 & 26.0 & 0.83 \\
\hline JW Dernbach (Eng) & 14.2 & 4 & 35.3 & 9.83 & 21.5 & 1.01 \\
\hline MN Samuels (WI) & 12.0 & 3 & 36.0 & 9.00 & 24.0 & 1.19 \\
\hline Shahid Afridi (Pak) & 24.0 & 4 & 42.8 & 7.12 & 36.0 & 1.45 \\
\hline Umar Gul (Pak) & 17.0 & 3 & 56.0 & 9.88 & 34.0 & 2.46 \\
\hline DL Vettori (NZ) & 16.0 & 2 & 51.5 & 6.43 & 48.0 & 2.52 \\
\hline GB Hogg (Aus) & 21.0 & 2 & 78.5 & 7.47 & 63.0 & 4.27 \\
\hline J Botha (SA) & 12.4 & 1 & 96.0 & 7.57 & 76.0 & 5.63 \\
\hline
\end{tabular}


Raza Hasan: Pakistan bowler Raza Hasan is ranked number six in the MRrankings. However, Raza is not in the list of top ten bowler using the FPC method. He bowled fifteen overs and took only three wickets for the whole tournament. His bowling average is 24.7, which is higher than all the players in both top ten lists. Raza's strike rate is 30.0, which is also higher than that of all the top ten bowlers in both top ten lists. While it is true that his economy rate is lower, he did not take enough tournament wickets, which a quality T20 bowler must do. The MR-ranking method appears to give too much weight to the economy rate variable without considering other informative factors, resulting in some distortion in its ranking context.

Timothy Southee: New Zealand bowler Timothy Southee is ranked number nine in the top ten list in FPC-rankings, but does not appear in the top ten list of the MR method. Timothy bowled 18 overs, took eight wickets, had an average of 18.0 with strike rate 13.5. His economy rate is a bit higher when compared to other top players; however, his bowling average is lower than that of Saeed Ajmal, who is ranked number nine in the MR-rankings. Also, Timothy has the third best strike rate in the whole tournament. This justifies why he is correctly ranked in the FPCrankings but not so in the MR-rankings.

\section{Conclusions}

In this article we have demonstrated a simple, yet straightforward, method for analyzing the performance of T20-World Cup Cricket 2012 players. The proposed method, based on principal component analysis, is transparent and can be directly applied to the type of correlated data routinely found in cricket, as well as other team sports. We compared our method with the T20-World Cup 2012 analysis published by Madhusudhan Ramakrishnan of ESPNcricinfo, and eight of the ten top batsmen and eight of the ten top bowlers agree under both methods. Specific examples were further studied demonstrating the superiority the FPC method. The ability of the First Principal Component method to consistently capture a significant portion of the variability in cricket athletic performance is the key strength of the proposed method, which offers a transparent alternative for the cricket-playing community.

\section{References}

1. Bennet, J. (1998) Statistics in Sports, Oxford University Press Inc., pp 93-95.

2. Borooah Vani K. and Mangan John E. (2010) "The "Bradman Class": An Exploration of Some Issues in the Evaluation of Batsmen for Test Matches, 1877-2006," Journal of Quantitative Analysis in Sports: Vol. 6 : Iss. 3, Article 14.

3. Dawkins, B. (1989), "Multivariate Analysis of National Track Records." The American Statistician, 43, 100-115, DOI: $10.2307 / 2684514$, DOI: 10.1080/00031305.1989.10475631.

4. Johnson, R. A., and Wichern, D. W. (2007), Applied Multivariate Statistical Analysis (6th ed.), Upper Saddle River, NJ: Prentice Hall. 
5. Lakkaraju, P. and S Sethi, S. (2012). Correlating the Analysis of Opinionated Texts Using SAS ${ }^{\circledR}$ Text Analytics with Application of Sabermetrics to Cricket Statistics, Proceedings of SAS Global Forum 2012

6. Naik, D. N., and Khattree, R. (1996), "Revisiting Olympic Track Records: Some Practical Considerations in the Principal Component Analysis." The American Statistician, 50(2), 140-144, DOI: $10.2307 / 2684425$, DOI: $10.1080 / 00031305.1996 .10474361$

7. Ramakrishnan, M. (2012) " An analysis of individual batting and bowling performances in the World Twenty20 2012" [online]. Available at http://www.espncricinfo.com/icc-world-twenty202012/content/story/586148.html.

8. van Staden, P. J. (2008) "Comparison of bowlers, batsmen and all-rounders in cricket using graphical displays", Technical Report 08/01, Department of Statistics, Faculty of Natural and Agricultural Sciences, University of Pretoria.

9. Watnik , M. and Levine, R A., (2001), "NFL Y2K PCA," Journal of Statistics Education, 9, 3. Available at http://www.amstat.org/publications/jse/v9n3 /datasets.watnik.html 